\title{
The Formation and Stability of Carbonic Acid on Outer Solar System Bodies
}

\author{
Z. Peeters ${ }^{\mathrm{a}, \mathrm{b}}$, R. L. Hudson ${ }^{\mathrm{a}, \mathrm{c}}$, M. H. Moore ${ }^{\mathrm{a}}$, Ariel Lewis ${ }^{\mathrm{c}}$ \\ ${ }^{a}$ Code 691, NASA Goddard Space Flight Center, Greenbelt, MD 20771 \\ ${ }^{b}$ Department of Chemistry, The Catholic University of America, Washington, DC 20064 \\ ${ }^{\mathrm{c} D}$ Department of Chemistry, Eckerd College, St. Petersburg, FL 33711
}

Manuscript pages: 40 (Text: 16 pages)

Figures: 9

Tables: 6 


\begin{abstract}
The radiation chemistry, thermal stability, and vapor pressure of solid-phase carbonic acid $\left(\mathrm{H}_{2} \mathrm{CO}_{3}\right)$ have been studied with mid-infrared spectroscopy. A new procedure for measuring this molecule's radiation stability has been used to obtain intrinsic IR band strengths and half-lives for radiolytic destruction. Results are compared to literature values. We report, for the first time, measurements of carbonic acid's vapor pressure and its heat of sublimation. We also report the first observation of a chemical reaction involving solid-phase carbonic acid. Possible applications of these findings are discussed, with an emphasis on the outer Solar System.
\end{abstract}

Key Words: Ices, IR Spectroscopy; Satellites, Surfaces; Cosmic Rays 
the closest planet. In each case, carbonic acid may be formed, and for Callisto a tentative detection of $\mathrm{H}_{2} \mathrm{CO}_{3}$ already has been made (Johnson et al., 2004).

To assess the formation and stability of carbonic acid in the Solar System, it is important to investigate the molecule's physical and chemical properties, but little such work has been published to date. Gerakines et al. (2000) compared the yields of $\mathrm{H}_{2} \mathrm{CO}_{3}$ made by exposing $\mathrm{H}_{2} \mathrm{O}+\mathrm{CO}_{2}$ ice mixtures to ion irradiation $\left(\sim 1 \mathrm{MeV} \mathrm{H}{ }^{+}\right)$and to $\mathrm{UV}$ photons $(\sim 10 \mathrm{eV})$. The same researchers measured carbonic acid's intrinsic IR band strengths by the growth of products resulting from $\mathrm{UV}$ destruction of $\mathrm{H}_{2} \mathrm{CO}_{3}$. Earlier work also showed qualitatively that carbonic acid's vapor pressure is lower than that of $\mathrm{H}_{2} \mathrm{O}, \mathrm{CO}_{2}$, and the observed reaction products, since $\mathrm{H}_{2} \mathrm{CO}_{3}$ is the last of these to sublime under vacuum in the $200-250 \mathrm{~K}$ region (Moore and Khanna, 1991). A white color is likely for $\mathrm{H}_{2} \mathrm{CO}_{3}$ made by acid-base chemistry (photographs in Loerting et al., 2000), and the work by Winkel et al. (2007) showed that the x-ray powder pattern of frozen $\mathrm{H}_{2} \mathrm{CO}_{3}$ is featureless. To our knowledge, little else, if anything, is known of solid-phase carbonic acid from experiments.

In this paper, we reinvestigate the intrinsic IR band strengths of $\mathrm{H}_{2} \mathrm{CO}_{3}$ and, for the first time, measure this molecule's radiolytic destruction at several temperatures. These new radiation experiments take into account amorphization of the sample. Furthermore, the highest temperature at which destruction measurements are made has been raised from $\sim 10 \mathrm{~K}$ to $200 \mathrm{~K}$. Temperature-dependent changes in the position and width of the $\mathrm{H}_{2} \mathrm{CO}_{3}$ feature at $2618 \mathrm{~cm}^{-1}(3.82 \mu \mathrm{m})$ have been recorded. The first measurements of the vapor pressure and heat of vaporization of pure $\mathrm{H}_{2} \mathrm{CO}_{3}$ are given, along with the first example of a low-temperature acid-base reaction of the molecule. 
Changes in the IR spectra of irradiated ices were followed by Fourier-transform infrared (FTIR) spectroscopy using a Nicolet Nexus 760 instrument. In this setup, the incident IR beam passed through the sample, was reflected by the underlying aluminum mirror, and then passed through the ice a second time, and to the IR detector, for what are sometimes called transmission-reflection-transmission spectra. Measurements were made at $2-\mathrm{cm}^{-1}$ resolution from 5000 to $650 \mathrm{~cm}^{-1}$, averaged over 150 scans.

For studying the vapor pressure of $\mathrm{H}_{2} \mathrm{CO}_{3}$, the compound first was made by an acid-base reaction between a 1 molar solution of $\mathrm{HBr}$ (Sigma-Aldrich) and a 0.1 molar solution of $\mathrm{KHCO}_{3}$ (Sigma-Aldrich), similar to the technique of Hage et al. (1993). A few microliters of the $\mathrm{KHCO}_{3}$ solution were injected through a septum, using a syringe, onto a $\mathrm{KBr}$ substrate at $10 \mathrm{~K}$, attached to the tail section of a closed-cycle helium cryostat. Next, a few microliters of the $\mathrm{HBr}$ solution were injected the same way to form a layer atop the frozen $\mathrm{KHCO}_{3}$ solution. This process was repeated about ten times to increase the ice's thickness. Subsequent warming of the sample to $\sim 200 \mathrm{~K}$ removed the $\mathrm{H}_{2} \mathrm{O}$ and initiated a reaction between $\mathrm{HBr}$ and $\mathrm{KHCO}_{3}$ to form $\mathrm{H}_{2} \mathrm{CO}_{3}$, changes that were followed with IR spectroscopy. The sample then was heated to $240-255 \mathrm{~K}$, and IR spectra recorded over time, with a focus on the 1300 and $1500 \mathrm{~cm}^{-1}$ features of $\mathrm{H}_{2} \mathrm{CO}_{3}$. Band areas were measured and combined with intrinsic band strengths, so called $A$ values, to determine the vapor pressures and enthalpy of sublimation $\left(\Delta \mathrm{H}_{\mathrm{sub}}\right)$ of $\mathrm{H}_{2} \mathrm{CO}_{3}$ (Khanna et al., 1990). These measurements were made with a Mattson Polaris spectrometer operating in a conventional transmission mode. 


\subsection{Radiolytic destruction}

The destruction of crystalline $\mathrm{H}_{2} \mathrm{CO}_{3}$ by $0.8 \mathrm{MeV}$ protons was followed by measuring the decrease in IR band areas after various doses. As an example, Figs. 3a and $3 \mathrm{~b}$ compare spectra in the $2900-1500 \mathrm{~cm}^{-1}(3.45-6.67 \mu \mathrm{m})$ region before and after irradiation to a dose of $2.0 \mathrm{eV}$ molecule ${ }^{-1}$. The $\mathrm{H}_{2} \mathrm{CO}_{3}$ bands are seen to decrease, indicating a loss of molecules, and at the same time $\mathrm{H}_{2} \mathrm{O}$ and $\mathrm{CO}_{2}$ are formed $\left(\mathrm{H}_{2} \mathrm{O}\right.$ is not shown). In addition, irradiation caused the $\mathrm{H}_{2} \mathrm{CO}_{3}$ bands to widen, indicating amorphization of the crystalline sample.

To accurately quantify carbonic acid's radiolytic destruction it was necessary to distinguish between spectral changes caused by (a) loss of $\mathrm{H}_{2} \mathrm{CO}_{3}$ molecules and (b) amorphization. This was done by warming the sample to $200 \mathrm{~K}$ after each irradiation step to fully recrystallize the partially-amorphous ice and to sublime away the $\mathrm{H}_{2} \mathrm{O}$ and $\mathrm{CO}_{2}$ formed by radiolysis. The ice then was recooled to $14 \mathrm{~K}$, as shown in Fig. 3c, for comparison to the original spectrum of the unirradiated ice, Fig. 3a. The spectra of Figs. $3 \mathrm{a}$ and $3 \mathrm{c}$ are similar, but the latter has slightly smaller $\mathrm{H}_{2} \mathrm{CO}_{3}$ bands, caused by the destruction of crystalline $\mathrm{H}_{2} \mathrm{CO}_{3}$.

The normalized band areas for $\mathrm{H}_{2} \mathrm{CO}_{3}$ have been plotted in Fig. 4 as a function of radiation dose. Table 2 lists all bands that were averaged for this graph along with their integration limits. Also in Fig. 4 are linear regression lines through the data points. The corresponding half-life doses for $\mathrm{H}_{2} \mathrm{CO}_{3}$ irradiated at 14,100 , and $200 \mathrm{~K}$ are then 11,11 , and $7 \mathrm{eV} \mathrm{molec}^{-1}$, respectively. 
temperature. After this annealing cycle, some $\mathrm{CO}_{2}$ often remained trapped in the $\mathrm{H}_{2} \mathrm{CO}_{3}$ (Fig. 3c). In order to relate only the amount of $\mathrm{CO}_{2}$ formed to the amount of $\mathrm{H}_{2} \mathrm{CO}_{3}$ destroyed, at each radiation step we subtracted the band area of any remaining $\mathrm{CO}_{2}$ in the annealed ice from the area of the $\mathrm{CO}_{2}$ band recorded after the next irradiation. Table 3 gives the results of these $A\left(\mathrm{H}_{2} \mathrm{CO}_{3}\right)$ measurements at 14 and $100 \mathrm{~K}$, corrected for amorphization. Because most of the $\mathrm{CO}_{2}$ product immediately sublimed away upon formation at $200 \mathrm{~K}$, no band strengths were determined at that temperature. Note that the measurements in Table 3 are based on $A\left(\mathrm{CO}_{2}\right)=7.6 \times 10^{-17} \mathrm{~cm} \mathrm{molec}^{-1}$ (Gerakines et al., 1995), and that no decomposition of $\mathrm{H}_{2} \mathrm{CO}_{3}$ into $\mathrm{CO}$ appeared to occur. A few experiments with $\mathrm{H}_{2}{ }^{13} \mathrm{CO}_{3}$ were conducted to verify that all of the $\mathrm{CO}_{2}$ formation observed in our work was due to the proton irradiation, and not from leaks in the vacuum system. No such contamination was detected in any experiment.

\subsection{Radiation yield of $\mathrm{H}_{2} \mathrm{CO}_{3}$}

The radiation-chemical yield, denoted $G$, of a substance is the number of molecules produced by absorption of $100 \mathrm{eV}$. Previously-reported values for $G\left(\mathrm{H}_{2} \mathrm{CO}_{3}\right)$ from $\mathrm{H}_{2} \mathrm{O}+\mathrm{CO}_{2}(1: 1)$ ices at $14 \mathrm{~K}$ were $0.028,0.030$, and 0.02 for $\mathrm{MeV}$ protons and $\mathrm{UV}$ photons (Gerakines et al., 2000), and for $10 \mathrm{keV}$ electrons (Hand et al., 2007), respectively. These values were based on the growth of $\mathrm{H}_{2} \mathrm{CO}_{3}$ IR bands as a function of radiation dose, and represent the formation of $\mathrm{H}_{2} \mathrm{CO}_{3}$ within an amorphous ice mixture dominated by $\mathrm{H}_{2} \mathrm{O}$ and $\mathrm{CO}_{2}$. We repeated this type of experiment by irradiating $\mathrm{H}_{2} \mathrm{O}+$ $\mathrm{CO}_{2}(1: 1)$ at $14 \mathrm{~K}$ and $50 \mathrm{~K}$ in small steps, the $1500 \mathrm{~cm}^{-1}$ band's area being measured after each irradiation. The column density of $\mathrm{H}_{2} \mathrm{CO}_{3}$ was calculated from equation (1) 
and this may account for the $8-18 \mathrm{~cm}^{-1}$ shift of some bands with respect to their positions in the radiation-formed $\mathrm{H}_{2} \mathrm{CO}_{3}$.

Figure 6 shows the decrease in the normalized average areas for the 1300 and $1500 \mathrm{~cm}^{-1}$ bands of $\mathrm{H}_{2} \mathrm{CO}_{3}$ as a function of time at five different temperatures. Each decrease is related to a change in column density, the number of molecules per $\mathrm{cm}^{2}$ leaving the ice surface as a function of time. To determine column densities we used $A$ values measured at $100 \mathrm{~K}$. The slopes of similar non-normalized plots gave the sublimation fluxes (molec $\mathrm{m}^{-2} \mathrm{sec}^{-1}$ ) at each temperature. Equation (4) then was used to calculate the vapor pressure, $p$.

$$
\text { Sublimation Flux }=p /(2 \pi \mathrm{mkT})^{1 / 2}
$$

In (4), $\mathrm{m}$ is the mass of an $\mathrm{H}_{2} \mathrm{CO}_{3}$ molecule, $\mathrm{k}$ is the Boltzmann constant, and $\mathrm{T}$ is the absolute temperature, giving a vapor pressure in Newtons $\mathrm{m}^{-2}$, which was converted to units of bar. A plot of the calculated vapor pressure from 238 to $256 \mathrm{~K}$ is shown in Fig. 7a. Figure $7 \mathrm{~b}$ shows the same data graphed as $\ln (\mathrm{p})$ versus $1 / \mathrm{T}$, from which the slope gives the heat of sublimation as $\Delta \mathrm{H}_{\text {sub }}=65.2 \mathrm{~kJ} \mathrm{~mol}^{-1}$.

\subsection{Chemical destruction}

In addition to measurements of both the sublimation and the radiolytic destruction of solid $\mathrm{H}_{2} \mathrm{CO}_{3}$, we also have observed $\mathrm{H}_{2} \mathrm{CO}_{3}$ loss by chemical reaction. Previously, we found that ammonia $\left(\mathrm{NH}_{3}\right)$ blocks $\mathrm{H}_{2} \mathrm{CO}_{3}$ formation in irradiated solid-phase $\mathrm{H}_{2} \mathrm{O}+\mathrm{CO}_{2}$ $+\mathrm{NH}_{3}$ mixtures (Gerakines et al., 2000). In separate experiments, we have irradiated layered samples consisting of a mixture of solid $\mathrm{H}_{2} \mathrm{O}+\mathrm{CO}_{2}$ over a layer of $\mathrm{NH}_{3}$, both ices being formed at $\sim 10 \mathrm{~K}$. Subsequent irradiation produced $\mathrm{H}_{2} \mathrm{CO}_{3}$ in the upper layer, 
5 shows the results of such a calculation, giving a half-life for carbonic acid at $100 \mathrm{~K}$ on both Europa and Callisto.

The spectra we have recorded, such as in Fig. 1, illustrate the differences between carbonic acid in an amorphous matrix and pure crystalline $\mathrm{H}_{2} \mathrm{CO}_{3}$. On warming from 14 to $240 \mathrm{~K}$ (Figs. 1b and 1c), some peaks shift, some bands narrow, and some splittings are observed. As an example, the broad, weak band near $2555 \mathrm{~cm}^{-1}(3.914 \mu \mathrm{m})$ sharpens considerably and moves to $2612 \mathrm{~cm}^{-1}(3.828 \mu \mathrm{m})$ on warming to $240 \mathrm{~K}$. Figure 2 shows that this same feature then displays small, reversible shifts in position as the temperature of the carbonic acid is changed. The importance of documenting such spectral variations is demonstrated by Fig. 9, which overlays this same $\mathrm{OH}$ stretching feature of carbonic acid on reflectance spectra of Callisto and Europa. The spectrum of pure crystalline $\mathrm{H}_{2} \mathrm{CO}_{3}$ is shown as is one in which carbonic acid is trapped in an amorphous ice mixture. It is seen that the band shape and position for the amorphous ice provides the better fit. Any similar feature on Europa is within the noise of the data as demonstrated in Fig. 9. See Johnson et al. (2004) for a suggestion of $\mathrm{H}_{2} \mathrm{CO}_{3}$ as a possible candidate for Callisto. Additional details on the shifts and intensity changes of $\mathrm{H}_{2} \mathrm{CO}_{3}$ features can be found in Winkel et al. (2007).

Our analysis of data from irradiated $\mathrm{H}_{2} \mathrm{CO}_{3}$ considers both radiation-induced chemistry and radiation-induced amorphization. Separating these effects is important because measurements of both $\mathrm{H}_{2} \mathrm{CO}_{3}$ loss and $\mathrm{CO}_{2}$ growth are needed for an accurate determination of intrinsic IR band strengths of carbonic acid. Along these lines, the band strengths we report in Table 3 are significantly different $(>50 \%)$ from some of the older, uncorrected values. 
$\left(25.2 \mathrm{~kJ} \mathrm{~mol}^{-1}\right)$, which will assist $\mathrm{H}_{2} \mathrm{CO}_{3}$ in remaining on planetary surfaces after the sublimation of the other two molecules. For comparison to other carboxylic acids, $\Delta \mathrm{H}_{\text {sub }}$ is $62.5 \mathrm{~kJ} \mathrm{~mol}^{-1}$ for formic acid $(\mathrm{HCOOH})$ and $67.9 \mathrm{~kJ} \mathrm{~mol}^{-1}$ for acetic acid $\left(\mathrm{CH}_{3} \mathrm{COOH}\right)$. See Calis-Van Ginkel et al. (1978).

Having discussed our results, it is appropriate to point out some limitations and possible future work. Two sources of error in Table 1 are the unknown density and radiation stopping power of a $1: 1 \mathrm{H}_{2} \mathrm{O}+\mathrm{CO}_{2}$ ice. Our approach was simply to assume these quantities to be an average of the values of the individual components. A direct measurement, particularly of the density, is desirable.

The $\mathrm{H}_{2} \mathrm{CO}_{3}$ formation we report is for this molecule generated in an amorphous mixture of $\mathrm{H}_{2} \mathrm{O}+\mathrm{CO}_{2}(1: 1)$. However, to quantify carbonic acid production we were forced to use our $A$ values for crystalline $\mathrm{H}_{2} \mathrm{CO}_{3}$. The reason for this is that neither of the synthetic techniques we used to prepare $\mathrm{H}_{2} \mathrm{CO}_{3}$ resulted in the pure amorphous material. To our knowledge, pure amorphous $\mathrm{H}_{2} \mathrm{CO}_{3}$ has not yet been made and so no spectra or band strengths are available. A related difficulty concerned the purity of the carbonic acid in our vapor pressure measurements. The acid-base reaction used to make $\mathrm{H}_{2} \mathrm{CO}_{3}$ gave $\mathrm{KBr}$ as a by-product. This is not expected to alter the vapor pressures of Fig. 7, but a check is desirable, such as with $\mathrm{H}_{2} \mathrm{CO}_{3}$ made by a different method.

We also note that our vapor-pressure work was done with an IR spectrometer operating in a conventional transmission mode, while measurements of radiolytic destruction utilized reflection spectroscopy. The spectra in the two cases were essentially identical, as seen in Fig. 5. 


\section{References}

Brown, R. H., Clark, R. N., Buratti, B. J., Cruikshank, D. P., Barnes, J. W., Mastrapa, R. M. E., Bauer, J., Newman, S., Momary, T., Baines, K. H., and 15 coauthors, 2006. Composition and physical properties of Enceladus' surface. Science $311,1425-1428$.

Brucato J. R., Palumbo M. E., Strazzulla, G., 1997. $\mathrm{H}_{2} \mathrm{CO}_{3}$ by ion implantation in water/carbon dioxide ice mixtures. Icarus 125, 135-144.

Calis-Van Ginkel, C. H. D., Calis, G. H. M., Timmermans, C. W. M., DeKruif, C. G., Oonk, H. A. J., 1978. Enthalpies of sublimation and dimerization in vapor-phase of formic, acetic, propanoic and butanoic acids. J. Chem. Thermodyn. 1978, 10, $1083-1088$.

Clark, R. N., Curchin, J. M., Jaumann, R., Cruikshank, D. P., Brown, R. H., Hoefen, T. M., Stephan, K., Moore, J. M., Buratti, B. J., Baines, K. H., Nicholson, P. D., Nelson, R. M., 2008. Compositional mapping of Saturn's satellite Dione with Cassini VIMS and implications of dark material in the Saturn system. Icarus 193, 372-386.

Cooper, J. F., Johnson, R. E., Mauk, B. H., Garrett, H. B., and Gehrels, N., 2001. Energetic ion and electron irradiation of the ice Galilean satellites. Icarus 149, 133-159.

DelloRusso, N., Khanna, R. K., Moore, M. H., 1993. Identification and yield of $\mathrm{H}_{2} \mathrm{CO}_{3}$ and formaldehyde in irradiated ices. J. Geophys. Res. E 98, 5505-5510. 
Grundy, W. M., Young, L. A., Spencer, J. R., Johnson, R. E., Young, E. F., Buie, M. W., 2006. Distributions of $\mathrm{H}_{2} \mathrm{O}$ and $\mathrm{CO}_{2}$ ices on Ariel, Umbriel, Titania, and Oberon from IRTF/SpeX observations. Icarus 184, 543-555.

Hage, W., Hallbrucker, A., Mayer, E., 1993. Carbonic acid: synthesis by protonation of bicarbonate and FTIR spectroscopic characterization via a new cryogenic technique. J. Am. Chem. Soc. 115, 8427-8431.

Hand, K. P., Carlson, R. W, Chyba, C. F., 2007. Energy, chemical disequilibrium, and geological constraints on Europa. Astrobiology 7, 1006-1022.

Hansen, G. B., McCord, T. B., 2008. Widespread $\mathrm{CO}_{2}$ and other non-ice compounds on the anti-Jovian and trailing sides of Europa from Galileo/NIMS observations. Geophys. Res. Lett. 35, L01202.

Hibbitts, C. A., McCord, T. B., Hansen, G. B., 2000. Distributions of $\mathrm{CO}_{2}$ and $\mathrm{SO}_{2}$ on the surface of Callisto. J. Geophys. Res. - Planets. 105, 22541-22558.

Hibbitts, C. A., Pappalardo, R. T., Hansen, G. B., McCord, T. B., 2003. Carbon dioxide on Ganymede. J. Geophys. Res. - Planets. 108, ID 5036.

Hudson, R. L., Moore, M. H., 2004. Reactions of nitriles in ices relevant to Titan, comets, and the interstellar medium: Formation of cyanate ion, ketenimines, and isonitriles. Icarus 172, 466-478.

Johnson, R. E., Carlson, R. W., Cooper, J. F., Paranicas, C., Moore, M. H., Wong, M. C., 2004. Radiation effects on the surfaces of the Galilean satellites. In: Bagenal, F., Dowling, T. E., McKinnon, W. B. (Eds.), Jupiter. The planet, satellites, and magnetosphere, vol. 1, Cambridge University Press, Cambridge, UK, 485-512. 
Winkel, K., Hage, W., Loerting, T., Price, S., Mayer, E., 2007. Carbonic acid: From polyamorphism to polymorphism. J. Am. Chem. Soc. 129, 13863-13871.

Wu, C. Y. R., Judge, D. L., Cheng, B., Yih, T., Lee, C. S., Ip, W. H., 2003. Extreme ultraviolet photolysis of $\mathrm{CO}_{2}-\mathrm{H}_{2} \mathrm{O}$ mixed ices at $10 \mathrm{~K}$. JGR-Planets. 108, 13-1 $-13-8$.

Zheng, W., Kaiser, R. I., 2007. On the formation of carbonic acid $\left(\mathrm{H}_{2} \mathrm{CO}_{3}\right)$ in solar system ices. Chem. Phys. Lett. 450, 55-60.

Ziegler, J. P., Biersack, J. P., Littmark, U., 1985. The stopping and range of ions in solids. Pergamon, New York. See also http://www.srim.org. 
Figure 5. A comparison of the IR spectra of $\mathrm{H}_{2} \mathrm{CO}_{3}$ formed by the irradiation of an $\mathrm{H}_{2} \mathrm{O}$ $+\mathrm{CO}_{2}(1: 1)$ ice and the acid-base reaction of warmed $\mathrm{HBr}+\mathrm{KHCO}_{3}$. The upper spectrum was taken with the reflection method described in the text, while the lower spectrum was recorded in a conventional transmission mode.

Figure 6. Normalized areas (averaged) of the 1300 and $1500 \mathrm{~cm}^{-1}$ bands of $\mathrm{H}_{2} \mathrm{CO}_{3}$ plotted as a function of time for five different temperatures. Each point is from the average area of the IR bands at 1300 and $1500 \mathrm{~cm}^{-1}$.

Figure 7. The vapor pressures of $\mathrm{H}_{2} \mathrm{CO}_{3}$ at five temperatures are shown. The slope of the regression line in the lower graph gives the heat of sublimation, $\Delta \mathrm{H}_{\text {sub }}=65.2 \mathrm{~kJ}$ $\mathrm{mol}^{-1}$.

Figure 8. The IR spectrum of the $\mathrm{H}_{2} \mathrm{CO}_{3}+\mathrm{NH}_{3}$ solid-phase reaction product compared to room-temperature ammonium carbonate, $\left(\mathrm{NH}_{4}\right)_{2} \mathrm{CO}_{3}$.

Figure 9: The IR reflection spectra of Europa and Callisto compared to spectra of crystalline $\mathrm{H}_{2} \mathrm{CO}_{3}$ at $140 \mathrm{~K}$ and $\mathrm{H}_{2} \mathrm{CO}_{3}$ mixed with $\mathrm{H}_{2} \mathrm{O}$ and $\mathrm{CO}_{2}$ at $150 \mathrm{~K}$. The $\mathrm{H}_{2} \mathrm{CO}_{3}$ absorbance spectra were inverted and arbitrarily scaled for this comparison. Callisto's observed $3.880 \mu \mathrm{m}\left(2577 \mathrm{~cm}^{-1}\right)$ feature is more similar to that of $\mathrm{H}_{2} \mathrm{CO}_{3}$ held in the amorphous ice. 
Figure 2
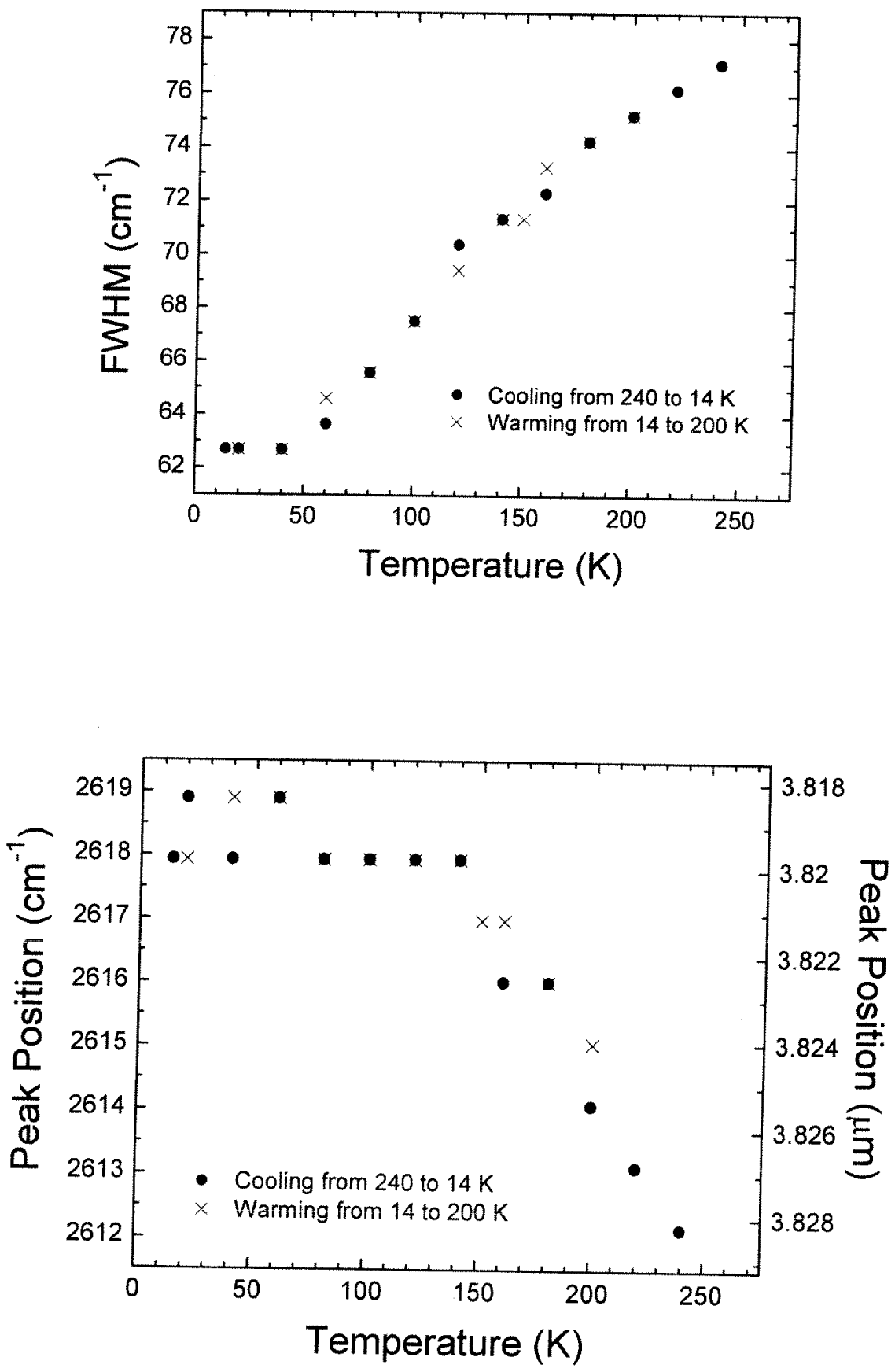
Figure 4

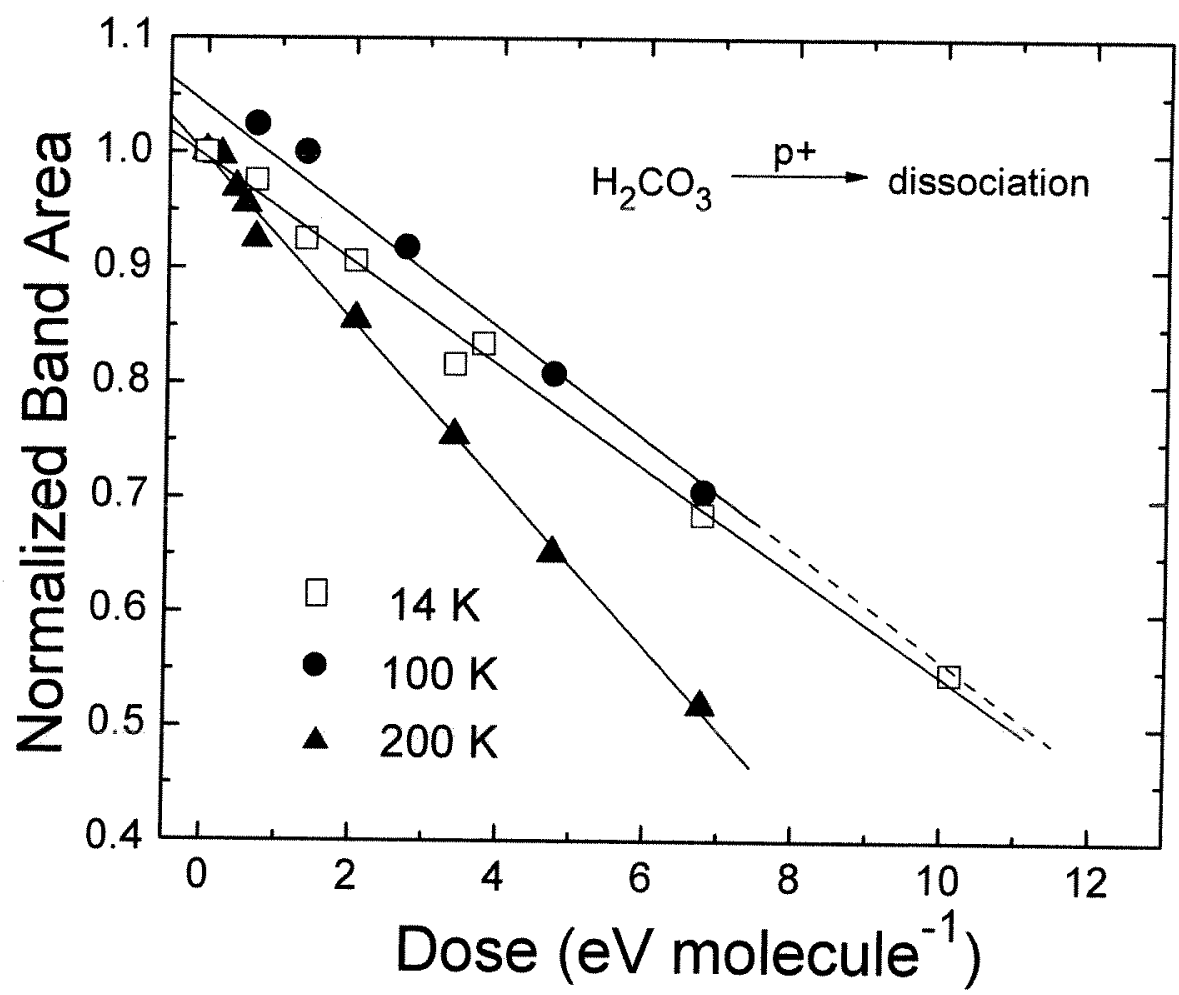


Figure 6

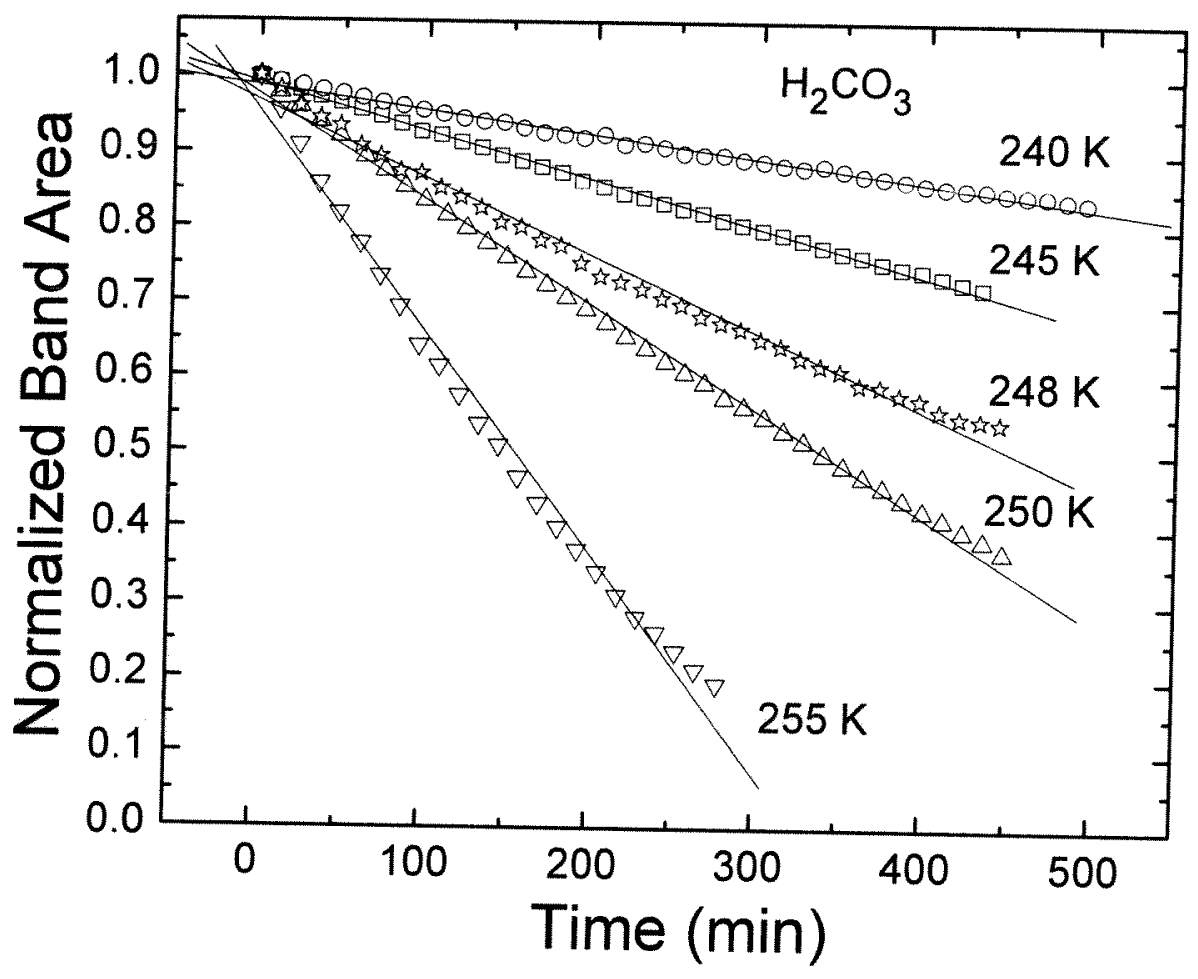


Figure 8

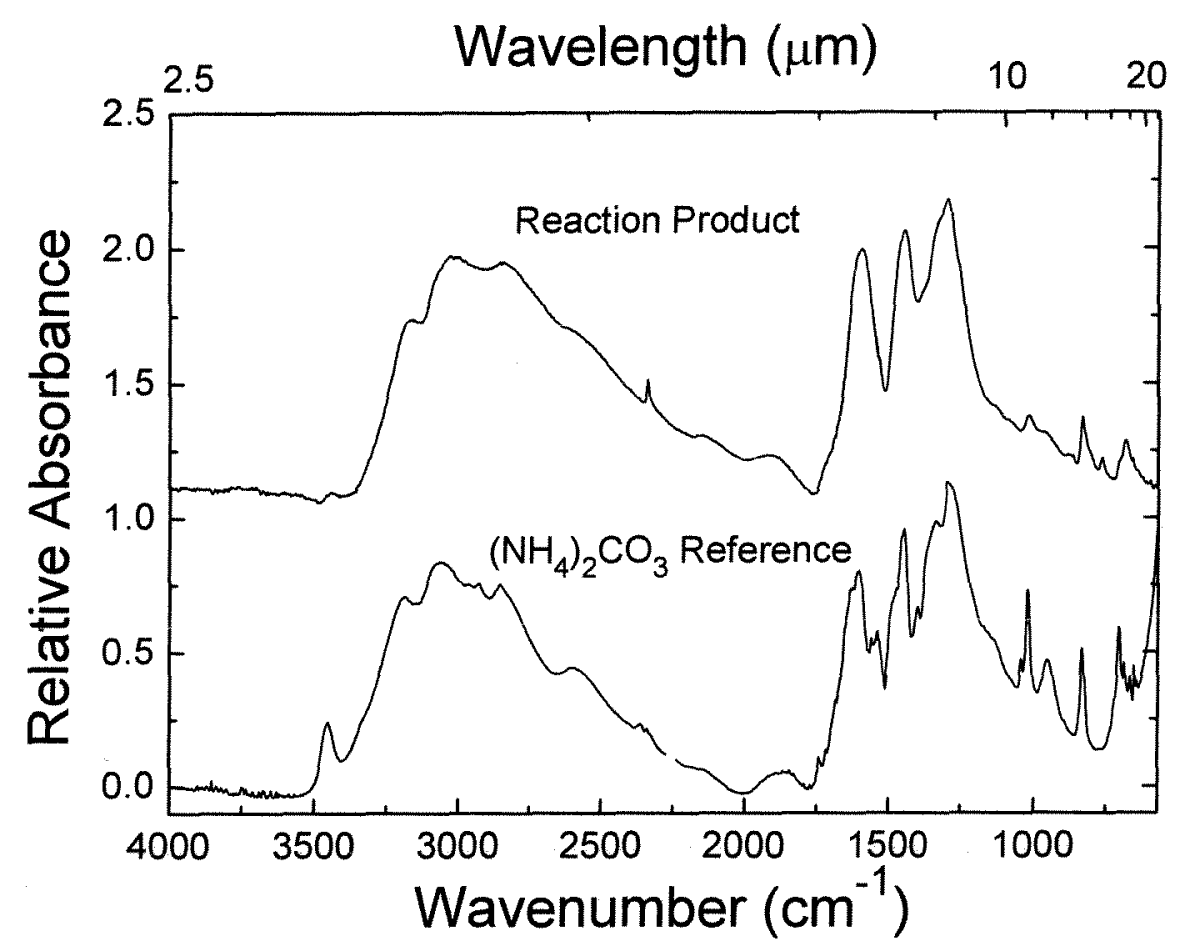


Table 1

Physical properties of ices

\begin{tabular}{cccc}
\hline Ice & $\begin{array}{c}\text { Molecular Mass } \\
\left(\mathrm{g} \mathrm{mol}^{-1}\right)\end{array}$ & $\begin{array}{c}\text { Density } \\
\left(\mathrm{g} \mathrm{cm}^{-3}\right)\end{array}$ & $\begin{array}{c}\text { Proton Stopping Power } \\
\left(\mathrm{MeV} \mathrm{cm}^{2} \mathrm{~g}^{-1}\right)^{\mathrm{c}}\end{array}$ \\
\hline $\mathrm{H}_{2} \mathrm{O}$ & 18 & 1 & 273 \\
$\mathrm{CO}_{2}$ & 44 & 1.7 & 240 \\
$\mathrm{H}_{2} \mathrm{O}+\mathrm{CO}_{2}(1: 1)$ & 31 & $1.35^{\mathrm{a}}$ & $256.5^{\mathrm{a}}$ \\
$\mathrm{H}_{2} \mathrm{CO}_{3}$ & 62 & $1^{\mathrm{b}}$ & 254 \\
\hline
\end{tabular}

${ }^{a}$ Average value for a $\mathrm{H}_{2} \mathrm{O}+\mathrm{CO}_{2}(1: 1)$ mixture.

${ }^{\mathrm{b}}$ Assumed value.

${ }^{\circ}$ Calculated for $0.8 \mathrm{MeV}$ protons, according to method of Zeigler et al. (1985). 
Table 3

IR band positions and strengths $(A)$ for $\mathrm{H}_{2} \mathrm{CO}_{3}$ at 14 and $100 \mathrm{~K}$

\begin{tabular}{cccccc}
\hline \multicolumn{2}{c}{ Band Position } & \multicolumn{3}{c}{$A\left(10^{-17} \mathrm{~cm} \mathrm{molec}^{-1}\right)$} \\
$\begin{array}{c}\text { Wavenumber } \\
\left(\mathrm{cm}^{-1}\right)\end{array}$ & $\begin{array}{c}\text { Wavelength } \\
(\mu \mathrm{m})\end{array}$ & & & & \\
\hline $2749+2833$ & $3.634+3.530$ & 5.3 & 3.3 & 9.8 & -- \\
2618 & 3.820 & 7.5 & 7.2 & 16.0 & - \\
1695 & 5.900 & 10.8 & 14.8 & 11 & 35 \\
1503 & 6.653 & 5.2 & 9.1 & 6.5 & 11 \\
1303 & 7.675 & 8.5 & 12.3 & 10 & 12.6 \\
1038 & 9.634 & 0.15 & 0.17 & 0.14 & - \\
875 & 11.43 & 4.5 & 2.8 & 5.6 & -- \\
\hline
\end{tabular}

${ }^{\mathrm{a}}$ From $18 \mathrm{~K}$ photodissociation of $\mathrm{H}_{2} \mathrm{CO}_{3}$ (Gerakines et al., 2000).

${ }^{b}$ From $185 \mathrm{~K}$ implantation of $\mathrm{H}^{+}$into $\mathrm{CO}_{2}$ ice to form $\mathrm{H}_{2} \mathrm{CO}_{3}$ (Garozzo et al., 2008). 


\section{Table 5}

Half-lives for crystalline $\mathrm{H}_{2} \mathrm{CO}_{3}$, based on the $100 \mathrm{~K}$ destruction rate in the laboratory, corrected for amorphization

\begin{tabular}{cccc}
\hline Environment & $\begin{array}{c}\text { Depth } \\
(\mu \mathrm{m})\end{array}$ & $\begin{array}{c}\text { Volume Dose } \\
\text { Rate } \\
\left(\mathrm{eV} \mathrm{molec} \mathrm{m} \mathrm{s}^{-1}\right)\end{array}$ & Half-Life \\
\hline Laboratory & 1.0 & $1.3 \times 10^{-3}$ & $2.4 \mathrm{~h}$ \\
Europa $^{\mathrm{a}}$ & 100 & $1.0 \times 10^{-8}$ & $35 \mathrm{y}$ \\
Callisto $^{\mathrm{a}}$ & 100 & $2.5 \times 10^{-11}$ & $1.4 \times 10^{4} \mathrm{y}$ \\
\hline
\end{tabular}

${ }^{a}$ Volume dose rates for Europa and Callisto from Cooper et al. (2001). 
